\title{
Effect of Different Parameters on Solar Pond Performance
}

\author{
Seyed Saeed Madani
}

Eastern Mediterranean University, Gazimağusa, NORTH CYPRUS

\begin{abstract}
By applying a model of finite differences, the thermal behavior of a large solar pond is studied in this paper. The 32-year data of sunny hour's today-length ratio are used for the estimation of global radiation. The temperature data of a similar duration are used for evaluating the ambient temperature. The effects of the variation of different zone thicknesses on pond performance are studied. It is observed that the upper convective zone thickness should be as thin as possible, the non-convective zone might be from 1 to $2 \mathrm{~m}$ and the lower convective zone thickness may be designed based on the application needs. A thicker non convective zone provides more insulation against heat losses, and a thicker lower convective one supplies a higher storage capacity, though with a lower operating temperature. The heat may be extracted from the pond by either a constant or a variable loading pattern. The appropriate loading pattern can be selected based on the needs and operational temperature. The LCZ temperature of the pond, under several heat extraction patterns, is also presented for practical applications.
\end{abstract}

Keywords: Salt gradient solar pond, solar energy

\section{INTRODUCTION}

Theoretical, as well as experimental research in this field has rarely been accomplished (Jaefarzadeh, 2000). Akbarzadeh and Ahmadi (Akbarzadeh \& Ahmadi, 1980) applied Weinberger's one-zone model for simulating the thermal performance of a large solar pond in the city of Shiraz in the southern part of Iran $\left(29^{\circ} 36^{\prime} \mathrm{N}, 52^{\circ} 33^{\prime} \mathrm{E}\right)$. However, in an analytical onezone model, the effects of the upper and lower convective zones are neglected. Toutounchi (Toutounchi, 1992) used Rabl and Nielsen's two-zone model for analyzing the performance of several solar ponds at various latitudes in Iran. Nevertheless, in a two-zone model, the influence of the upper convective zone is ignored. One-zone or two-zone simplified models are most useful if we are interested in obtaining a closed form analytical solution. However, as will be illustrated later, the negligence of convective layers may over-estimate the results, which will, in turn, introduce some errors into the solution. Moreover, the effects of the variation of the thermophysical properties of the fluid are also ignored in the calculations. In this research, we applied a numerical finite difference three-zone model for the thermal analysis of a large solar pond. Now, the three-zone model allows us to examine the effects of the variation of different parameters on pond performance. In this manner, we will be able to investigate several loading patterns, too. 


\section{Mathematical Formulation and Numerical Solution}

In a solar pond, saline is stored in three zones, increasing in density. The surface layer or upper convective zone, (UCZ), is homogeneous and convective, where the density of saline is close to fresh water. In the middle layer or non-convective zone, (NCZ), saline density increases in depth, thereby, natural convection is stopped. In this zone, mass or thermal energy is transported only by molecular diffusion which is a very slow process. The bottom layer or lower convective zone, (LCZ), is dense and convective, and has a relatively uniform density close to saline saturation. The part of solar irradiation which transmits to this zone increases its temperature. The heat stored there can only be transferred through the middle zone by conduction. Therefore, the non-convective zone acts as an insulator. The thermal energy collected in the storage zone may be utilized later. In a vertical system of coordinates, with $Z$ measured as positive downward, and $Z=0$ at the surface of the pond, Fig 26A,B. the transient equation of heat conduction in one dimension for the non-convective zone is written as.

$$
\rho C_{p} \frac{\partial T}{\partial t}=\frac{\partial}{\partial Z}\left(k \frac{\partial T}{\partial Z}\right)+H(Z, t) \quad D_{U} \leq Z \leq D_{U}+D_{N}
$$

where $\rho$ is the fluid density in $\mathrm{kg} / \mathrm{m}^{3}$. $_{\mathrm{P}}$ is the specific heat of the fluid in $\mathrm{J} / \mathrm{kg}^{\circ} \mathrm{C} . \mathrm{T}$ is the temperature in Celsius degrees, $t$ is the time, $k$ is the coefficient of heat conduction in $\mathrm{W} / \mathrm{m}^{\circ} \mathrm{C}$ $\mathrm{H}(\mathrm{Z}, \mathrm{t})$ is the energy absorbed in the body of the pond, Du is the thickness of the surface layer, and $D_{N}$ is the thickness of the gradient layer. The thermophysical properties for a saline solution pond, in terms of temperature $\mathrm{T}$, and salt concentration $\mathrm{c}$ in $\mathrm{kg} / \mathrm{m} 3$, are given by (Kaufmann, 1960).

$$
\begin{gathered}
k=0.5553-0.0000813 c+0.0008(T-20) \\
\rho=998+0.65 c-0.4(T-20) \\
C_{p}=4180+4.396 c+0.0048 c^{2}
\end{gathered}
$$

The solar irradiation absorbed in the body of the pond, $\mathrm{H}(\mathrm{Z}, \mathrm{t})$, is given by

$$
H=-\frac{d I_{R}(Z, t)}{d Z}
$$

where $I_{R}(Z, t)$, is the direct radiation flux in $W / m 2$ that reaches to a depth of $Z$ at any time, $t$. The wall shading effect may be neglected for large solar ponds. There are two boundary conditions at the upper interface, $Z=D_{U}$, and the lower interface, $Z=D_{U}+D_{N}$. For the upper boundary, it is assumed that the temperature of the UCZ is constant and equal to the ambient temperature.

$$
T=T_{a m b}
$$

This assumption has been applied in most similar models and confirmed by experimental observations. For the lower boundary condition, it is assumed that the temperature $\mathrm{T}_{\mathrm{L}}$ of LCZ is constant, and can be calculated from the energy conservation equation for the storage zone, giving

$$
\rho C_{p} D_{L} \frac{\partial T_{L}}{\partial t}=I_{R}+\left.k \frac{\partial T}{\partial Z}\right|_{Z=D_{U}+D_{N}}+\left.k_{G} \frac{\partial T}{\partial Z}\right|_{Z=D_{U}+D_{N}+D_{L}}-\frac{Q_{L}}{A}
$$


In Eq. (7), the LHS is the time variation of thermal energy in the unit area of the storage zone, and in the RHS, the first term is the radiation energy flux entering into the storage zone, the second term is the energy loss flux to the non-convective zone at the interface, the third term is the energy loss flux to the ground, and the last term is the extracted energy, $\mathrm{Q}_{\mathrm{L}}$, from the storage zone, per area, A, of the pond, in a loading period, $\mathrm{D}_{\mathrm{L}}$ is the thickness of the LCZ, and $\mathrm{kg}_{\mathrm{G}}$ is the coefficient of heat conduction from the bottom of the pond. It is assumed that the pond is large and the heat losses through the side walls may be neglected. The initial condition is obtained by assuming a uniform temperature profile at the start of the pond operation. Equation (1) may be discretized by an implicit finite difference scheme such as the Crank-Nicolson model

$$
\begin{aligned}
\rho_{i} C_{p i} \frac{T_{i}^{n+1}-T_{i}^{n}}{\Delta t}= & \frac{1}{2 \Delta Z^{2}}\left[k_{i+1 / 2}\left(T_{i+1}^{n+1}-T_{i}^{n+1}\right)+k_{i-1 / 2}\left(T_{i-1}^{n+1}-T_{i}^{n+1}\right)\right]+ \\
& \frac{1}{2 \Delta Z^{2}}\left[k_{i+1 / 2}\left(T_{i+1}^{n}-T_{i}^{n}\right)+k_{i-1 / 2}\left(T_{i-1}^{n}-T_{i}^{n}\right)\right]+H_{i}^{n+1 / 2}
\end{aligned}
$$

The upper boundary gives

$$
T_{1}^{n}=T_{a m b}^{n}
$$

The lower boundary becomes

$$
\rho C_{p} D_{L} \frac{\left(T_{L}^{n+1}-T_{L}^{n}\right)}{\Delta t}=I_{R}^{n}+k \frac{T_{M}^{n}-T_{L}^{n}}{\Delta Z}+k_{G} \frac{T_{G}^{n}-T_{L}^{n}}{\Delta S}-\frac{Q_{L}^{n}}{A}
$$

The temperature of the LCZ at the time of $1+n$ may be obtained from Eq. (10), explicitly as

$$
T_{L}^{n+1}=\frac{\Delta t}{\rho C_{P} D_{L}}\left[I_{R}^{n}+k \frac{T_{M}^{n}-T_{L}^{n}}{\Delta Z}+k_{G} \frac{T_{G}^{n}-T_{L}^{n}}{\Delta S}-\frac{Q_{L}^{n}}{A}\right]+T_{L}^{n}
$$

The implicit system of Eq. (8) with the boundary conditions of (9) and (11) may be solved using a double sweep algorithm [7].

\section{Solar Radiation And Attenuation In a Solar Pond}

\section{a) Estimation of solar radiation}

The direct or beam radiation in a region of altitude $h$ in kilometers above the mean sea level is given by [8]

$$
\left.I_{B}=I_{0}(1-0.14 h) \exp \left[-0.357\left(\sec \theta_{i}\right)^{0.678}\right]+0.14 h\right\}
$$

in which $\mathrm{I}_{0}=1353 \mathrm{~W} / \mathrm{m}^{2}$ is the solar constant, $\theta_{\mathrm{i}}$ is the zenith angle, or the angle between direct radiation and normal. This angle changes throughout the day, all year around and is given by

$$
\cos \theta_{i}=\cos \delta \cos \phi \cos \omega+\sin \delta \sin \phi
$$

in which $\delta$ is the angle of declination, $\varphi$ is the angle of latitude and $\omega$ is the hour angle.

The declination angle $\delta$ is defined in degrees by

$$
\delta=23.45 \sin \left(\frac{360(284+n)}{365.25}\right)
$$

where $\mathrm{n}$ is the day of the year. 
The hour angle $\omega$ is an angular measure of time, considered from noon based on local time, $\mathrm{h}$ and is defined thus

$$
\omega=\frac{2 \pi(h-12)}{24}
$$

The direct radiation on a horizontal plane is given by

$$
I_{H}=I_{B} \cos \theta_{1}
$$

Samimi [8] assumed that the diffuse radiation was $10 \%$ of the direct radiation for sunny days $(S=1)$, and $30 \%$ for cloudy days $(S=0)$. Therefore, the global radiation, $I_{G}$, is given by

$$
I_{G}=[S+0.1 S+0.3(1-S)] I_{B} \cos \theta_{i}
$$

where $S$ is the ratio of sunny hours to day length. The values of $S$ were obtained from the tables of the monthly average of sunny hours published by the Bureau of Meteorology. The available data were for 32 years from 1965 to 1996. The monthly average radiation on a horizontal surface may be obtained, using Eq. (16), summing it over a day, and over the days in a month averaging it. Having the mean value of $S$ in a month, the monthly average global radiation can be calculated from Eq. (17). A sinusoidal curve fitting the data of global radiation is given by

$$
\begin{aligned}
I_{G}= & 171.6-112.17 \cos (\omega t)-8.35 \sin (\omega t)+9.05 \cos (2 \omega t)+7.51 \sin (2 \omega t) \\
& +1.25 \cos (3 \omega t)+3.11 \sin (3 \omega t)-2.98 \cos (4 \omega t)-3.45 \sin (4 \omega t)
\end{aligned}
$$

where $\mathrm{IG}_{\mathrm{G}}$ is in $\mathrm{W} / \mathrm{m}^{2}, 1 \leq \mathrm{t} \leq 365$ is a day of the year, starting from January, and $\omega$ is the radian frequency.

b) Solar attenuation in the depth of a solar pond

Following Rabl and Nielsen (Rabl \& Nielsen, 1975), it is assumed that all the insolation that encounters the surface of a pond is beam radiation with the incidence angle fixed at 2 PM on the corresponding date. This assumption will not introduce errors of more than 5 percent into the model (Rabl \& Nielsen, 1975). The radiation that reaches to a certain depth is obtained from

$$
I_{R}=(1-R) \theta^{\prime} \tau I_{G}
$$

where $\mathrm{R}$ is the coefficient of reflection and is calculated from [10]

$$
R=\frac{1}{2}\left[\frac{\sin ^{2}\left(\theta_{i}-\theta_{r}\right)}{\sin ^{2}\left(\theta_{i}+\theta_{r}\right)}+\frac{\tan ^{2}\left(\theta_{i}-\theta_{r}\right)}{\tan ^{2}\left(\theta_{i}+\theta_{r}\right)}\right]
$$

$\theta_{\mathrm{r}}$ is the angle of refraction, and for water it is obtained from

$$
\sin \theta_{i}=1.33 \sin \theta_{r}
$$

In Eq. (20), $\tau$ is the attenuation function given by [11]

$$
\tau=0.36-0.08 \operatorname{Ln}\left(\frac{Z}{\cos \theta_{r}}\right)
$$


and the value of $\theta$ 'depends on many parameters such as the salt concentration, radiation propagation in water layers, bottom reflection, and water turbidity. Here we assume $\theta$ $'=0.85$, which has been assumed by other researchers (Akbarzadeh \& Ahmadi, 1980). In order to determine the effect of various parameters on the temperature of the LCZ, the following cases were studied.

1) Initial temperature of the pond: In Fig. 1, the temperatures of $10^{\circ} \mathrm{C}, 60^{\circ} \mathrm{C}, 80^{\circ} \mathrm{C}$ and $100^{\circ} \mathrm{C}$ were assumed as the initial temperatures of the pond. It is seen that, after a few months of the pond operation, the initial temperature has little effect on the LCZ temperature, and after one year, the maximum difference is about $2.5^{\circ} \mathrm{C}$. In all cases, the final temperature of the pond is about $80^{\circ} \mathrm{C}$. Consequently, in the next analysis, for studying the pond temperature in a quasi-steady state situation, this is taken as the starting temperature.

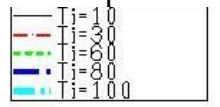

$L C Z$ Temperature

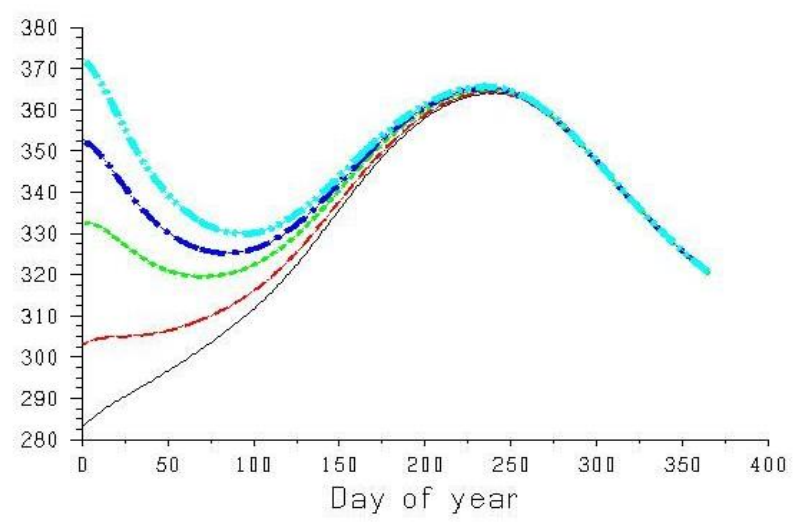

Fig1. The effect of the initial temperature on the performance of the pond

2) Thickness of the upper convective zone: the irregular growth of the UCZ thickness is one of the most common problems in the solar ponds. The most important causes are ascribed to the following factors.

- A large amount of the irradiation flux absorbed in a few centimeters near the surface of the pond produces a high temperature gradient

- The surface mixing caused by the wind driven currents erodes the NCZ and produces an upper zone of uniform density. The thickness of this zone depends on the intensity of the kinetic energy of the turbulent eddies, and may even reach to $1 \mathrm{~m}$ in severe conditions.

- The salt diffusion from the LCZ, as well as the evaporation, will increase the surface salinity that results in the generation of an upper convective layer. The lower boundary of this layer moves down to the level where the salinity in the gradient zone matches the increased salinity in the surface zone, so as to maintain the continuity of salinity across the boundary. In order to investigate the effect of the surface layer growth on pond performance, four different thicknesses of 0.0 , $0.2,0.4$, and $0.6 \mathrm{~m}$ were assumed for the UCZ. In Fig. 2, it is seen that when there is no $\mathrm{UCZ}$, the temperature of the $\mathrm{LCZ}$ rises to $130^{\circ} \mathrm{C}$. However, by increasing the thickness of the UCZ to $0.6 \mathrm{~m}$, the maximum temperature of the LCZ drops down to $112^{\circ} \mathrm{C}$. Therefore, in order to maximize the storage zone temperature, the thickness of the UCZ should be kept as thin as possible. The applications of 
floating rings and continuous surface flushing are highly recommended for the effective control and maintenance of a relatively thin UCZ (Jaefarzadeh \& Akbarzadeh, 2002). In practice, however, a thickness of $0.2 \mathrm{~m}$ is inevitable.

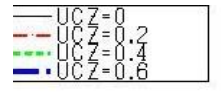

Temperature

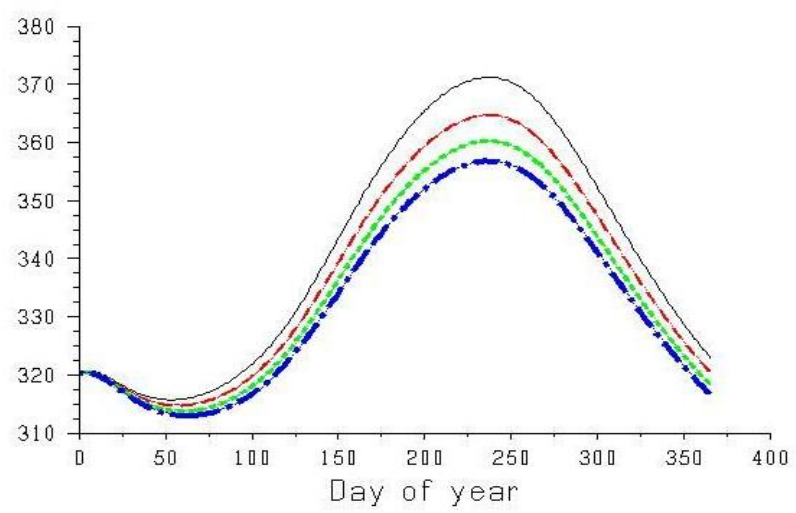

Fig. 2. The effect of the thickness of the UCZ on the performance of the pond

3) Thickness of the non-convective zone: In Fig. 3, the variation of the temperature of the storage zone is plotted for the thicknesses of $0.5,1,1.5$, and $2 \mathrm{~m}$ of the NCZ. As seen, an enhancing of the thickness of the NCZ will raise the temperature of the LCZ. This is expected because a thicker NCZ will provide more insulation and prevent heat losses from the storage zone to the ambient, although the temperature rise is not linearly proportional to the thickness growth. For instance, by increasing the thickness from 0.5 to $1 \mathrm{~m}$, the temperature growth will be about $30^{\circ} \mathrm{C}$, while an increase from 1 to 1.5 and then to $2 \mathrm{~m}$ will raise the maximum temperature by 15 and $6.5^{\circ} \mathrm{C}$, respectively. However, there are two factors that are not in favor of increasing the thickness of the NCZ. First, the amount of radiation flux that reaches the LCZ is reduced to the extent that for a thickness above approximately $2 \mathrm{~m}$ the storage zone temperature will be diminished. Second, the dynamic stability all over the NCZ, particularly at the upper and lower interfaces, may be shattered, resulting in the generation of internal convective layers that reduce the thermal storage considerably. 

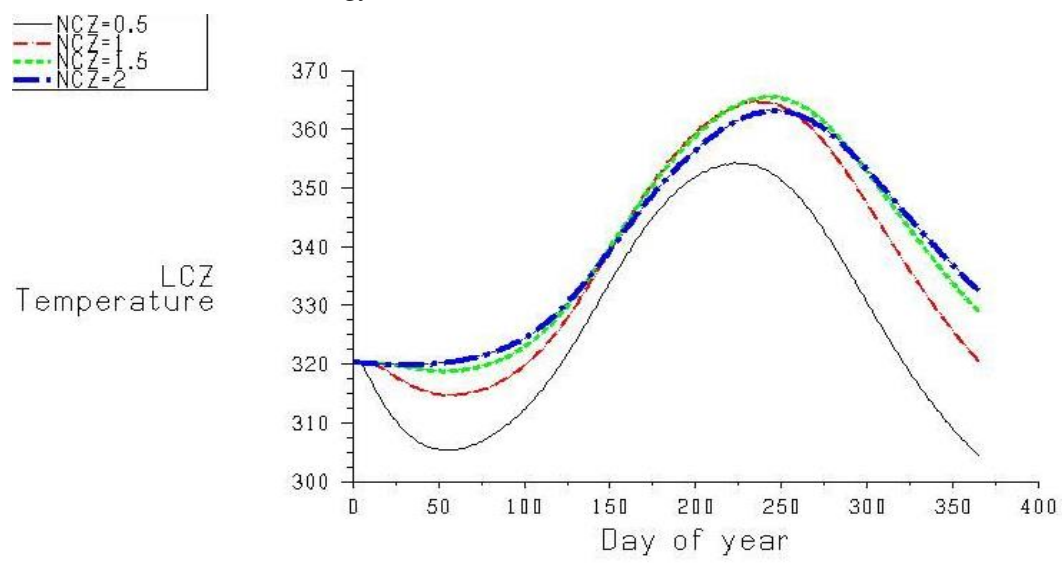

Fig. 3. The effect of the thickness of the NCZ on the performance of the pond

4) Thickness of the lower convective zone: For $\mathrm{NaCl}$ ponds, the dynamic stability requires a minimum thickness for the LCZ. An appropriate value for the thickness of the LCZ may be selected based on design considerations and operating temperature requirements. In Fig. 4, the storage zone temperature for various thicknesses of the LCZ is plotted. It can be observed that by increasing the thickness of the LCZ, the maximum temperature will be reduced, the minimum increased, and the mean temperature will remain approximately constant. In other words, due to an increase in the heat capacity of the storage zone, its temperature fluctuation is reduced. Therefore, where a relatively uniform low temperature is desired, a thick LCZ may be provided.

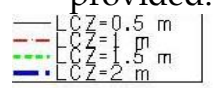

Temperature

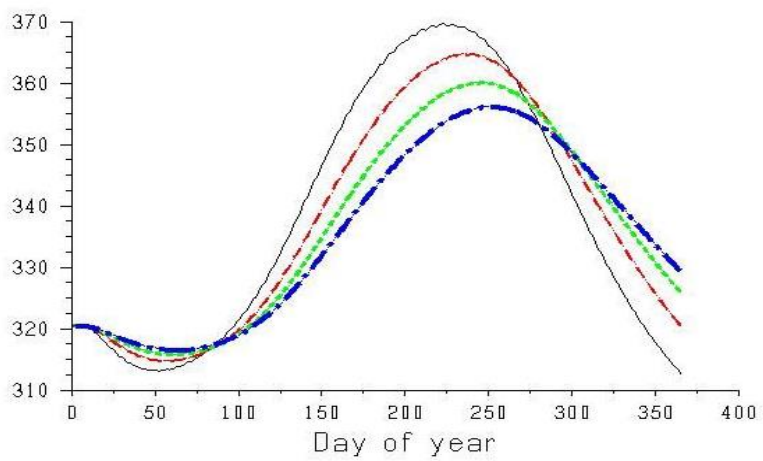

Fig. 4. The effect of the thickness of the LCZ on the performance of the pond

5) Coefficient of heat conductivity of the ground: Three cases of fully insulated ground $\left(\mathrm{k}_{\mathrm{G}}=0 \mathrm{~W} / \mathrm{m}^{\circ} \mathrm{C}\right)$, ground with a high coefficient of conductivity $\left(\mathrm{k}_{\mathrm{G}}=2.5 \mathrm{~W} / \mathrm{m}^{\circ} \mathrm{C}\right)$, and ground with very high coefficient of conductivity $\left(\mathrm{kG}=5 \mathrm{~W} / \mathrm{m}^{\circ} \mathrm{C}\right)$, were compared with the ordinary reference case $\left(\mathrm{kG}=0.96 \mathrm{~W} / \mathrm{m}^{\circ} \mathrm{C}\right)$. In Fig. 5, the temperature of the $\mathrm{LCZ}$ is plotted for various cases. It is seen that the ground heat loss, even in large solar ponds where the wall heat loss is normally ignored, has a major role in pond performance. Therefore, the bottom insulation, especially in cases where the phreatic surface is high and acts as a heat sink, is necessary, and will improve the pond 
temperature, considerably. This has been the subject of several investigations in the

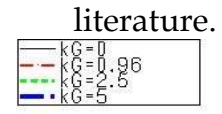

Temperature

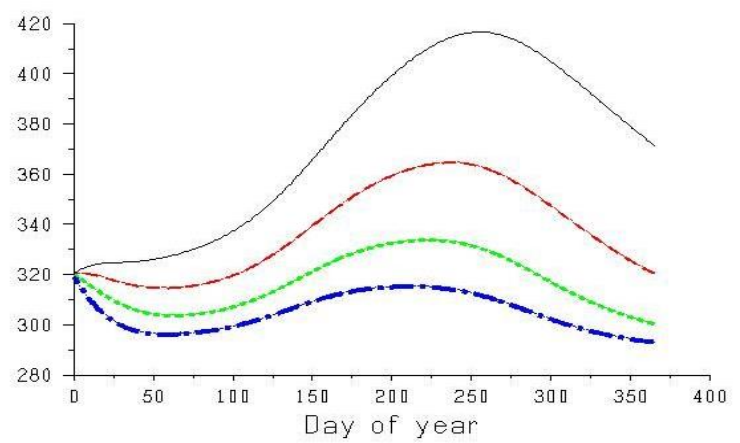

Fig 5. The effect of the coefficient of heat conductivity of the ground on the performance of the pond

\section{Heat Extraction Studies}

Heat extraction is the ultimate aim in a solar pond project. Any loading strategy is based on the temperature of the storage zone, the total amount of energy consumption, and its distribution during a year. Here, we study the performance of the pond, subject to several loading patterns, in the third year of its operation when the effect of the initial transitional stage is eliminated in fig 7-22 shows heat transfer analysis in 3 layers. In Fig. 6, the variation of the storage zone temperature of the reference pond is plotted for a $15 \%$ loading of the yearly average irradiation, and $15 \%$ loading of the daily average irradiation. The former loading pattern remains constant all through the year, while the latter is variable, however the total energy extraction in a year will be the same for both options. In the variable loading, more energy is extracted in the summer than in winter. Consequently, the temperature fluctuation of the LCZ will be reduced. This option is recommended when there is a need for a relatively uniform operating storage zone temperature. In the same figure, the ambient temperature, plus the LCZ temperature for no loading case, $25 \%$ loading of the daily average, and yearly average irradiation are drawn. It is seen that $25 \%$ of the constant loading will not be possible for about four months, when the temperature of the LCZ goes lower than the ambient temperature. For the variable loading pattern, heat can be extracted throughout the whole year. 


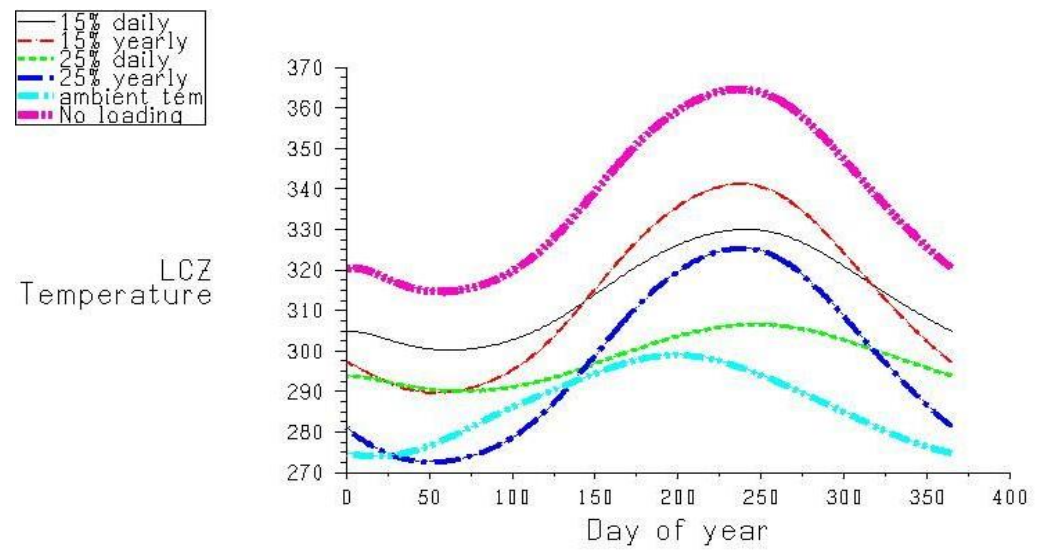

Fig. 6. The effect of loading on the performance of the pond

\section{Conclusions}

A mathematical model of finite difference has been applied for the analysis of the thermal behavior of a large solar pond. The storage zone temperature is obtained for the various thicknesses of the upper, middle, and lower zones. It is concluded that the upper convective zone should be kept as small as possible. The thickness of the middle nonconvective zone may not be less than $1 \mathrm{~m}$ because it acts as an insulating layer, and in the case of lower thicknesses, too much thermal energy may be lost through this layer. It is not recommended that it be more than $2 \mathrm{~m}$ due to the risk of instability and reduction of irradiation that reaches the storage zone. The thickness of the lower convective zone may be designed based on the needs and applications of the thermal energy. Ground heat loss has a major role in the storage zone temperature, thus bottom insulation is recommended for a better performance. Heat was extracted from the reference pond in the variable form of a fraction of daily irradiation and in the constant form of a fraction of yearly irradiation. It is observed that the LCZ temperature fluctuation in variable heat removal is less than in constant heat extraction. Based on the operational temperature, the appropriate loading pattern can be selected. However, if the maximum of the daily average of the ambient temperature is taken as a criterion, the maximum heat removal from the pond cannot be more than $22 \%$ for the variable loading, and about $15 \%$ for the constant loading.

\section{REFERENCES}

Akbarzadeh, A. A. \& Ahmadi, G. (1980). Computer simulation of the performance of a solar pond in the southern part of Iran, Solar Energy, 24, 143-151.

Anderson, D. A., Tannehill, J. C. \& Pletcher, R. H. (1989). Computational fluid mechanics and heat transfer. Hemisphere Publishing Corporation.

Brayant, H. C. \& Colbeck, I. (1983). A solar pond for London, Solar Energy, 19, 321.

Hull, J. R., Liu, K. V., Sha, W. T., Kamal, J. \& Nielson, C. E. (1984). Dependence of ground heat loss upon solar pond size and perimeter insulation: calculated and experimental results. Solar Energy, 33, p. 25.

Jaefarzadeh, M. R. \& Akbarzadeh, A. (2002). Towards the design of low maintenance salinity gradient solar ponds, Solar Energy, 73(5), 375-384.

Jaefarzadeh, M. R. (2000). Design, construction and analysis of the performance of a small salinity gradient solar pond. Research Report (in: Persian), Ferdowsi University of Mashhad, p. 195. 
Asia Pacific Journal of Energy and Environment, Volume 1, No 1 (2014)

Kaufmann, D. W. (1960). Sodium chloride, Reinhold, Network.

Rabl, A. \& Nielsen, C. E. (1975). Solar ponds for space heating. Solar Energy, 17, 1-12.

Samimi, J. (1986). Solar energy for Iran (in: Persian), J. of Physics, No. 3, 79-105.

Sukhatme, S. P. (1984). Solar energy. Tata Mc Graw-Hill Pub. Co., New Delhi.

Tabor, H. \& Weinberger, Z. (1981). Non-convecting solar ponds, chap. 10, in: Kreider, J. F. and Kreith, F. (Eds.), Solar Energy Handbook, Mc Graw Hill, New York.

Tabor, H. \& Weinberger, Z. (1981). Non-convecting solar ponds, chap. 10, in: Kreider, J. F. \& Kreith, F. (Eds.). Solar Energy Handbook, Mc Graw Hill, New York.

Toutounchi, G. H. (1992). Computer simulation of the performances of solar ponds in Iran. J. of Engineering, 5(3\&4), 141-144.

Wang, Y. F. \& Akbarzadeh, A. A. (1983). A parametric study on solar ponds. Solar Energy, 30 (6), $555-562$.

Zhang, Z. M. \& Wang, Y. F. (1990). A study on the thermal storage of the ground beneath solar ponds by computer simulation, Solar Energy, 44(5), 243-248. 


\section{Appendix}

Figure Caption

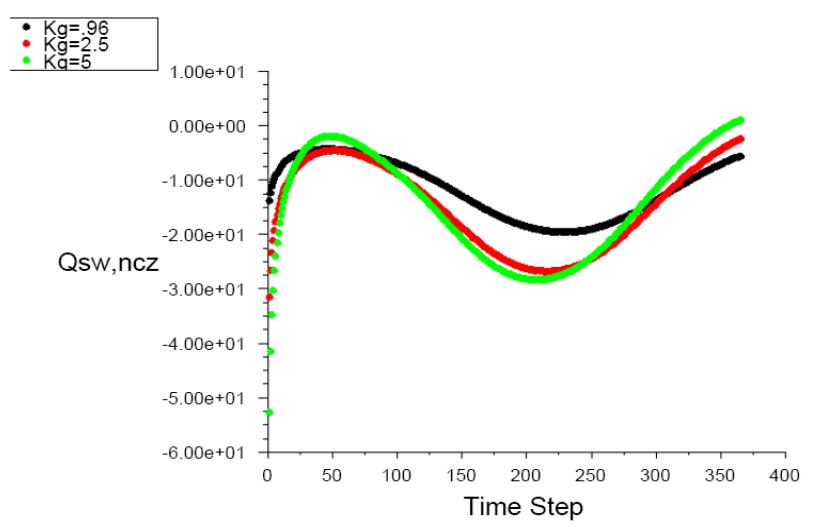

Fig 7. The effect of the kg on the Qsw,ncz

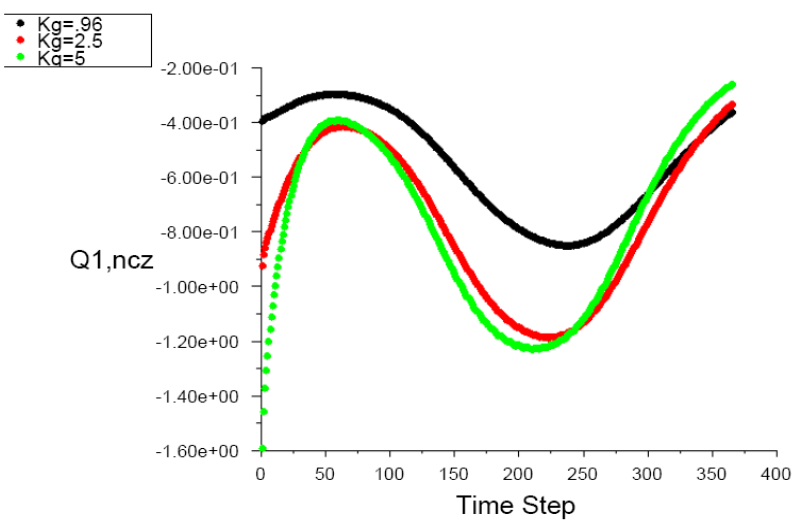

Fig 8.The effect of the $\mathrm{kg}$ on the Q1,ncz

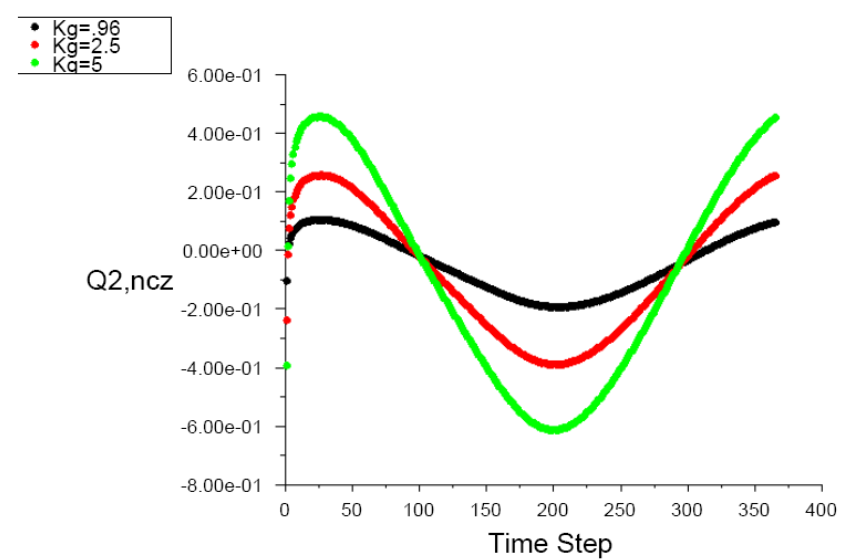

Fig. 9 The effect of the $\mathrm{kg}$ on the Q2,ncz 


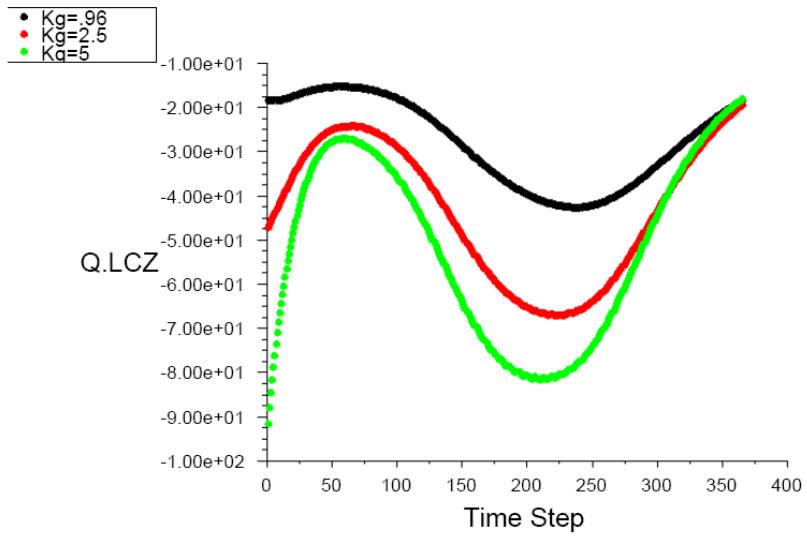

Fig. 10 The effect of the $\mathrm{kg}$ on the Q,LCZ

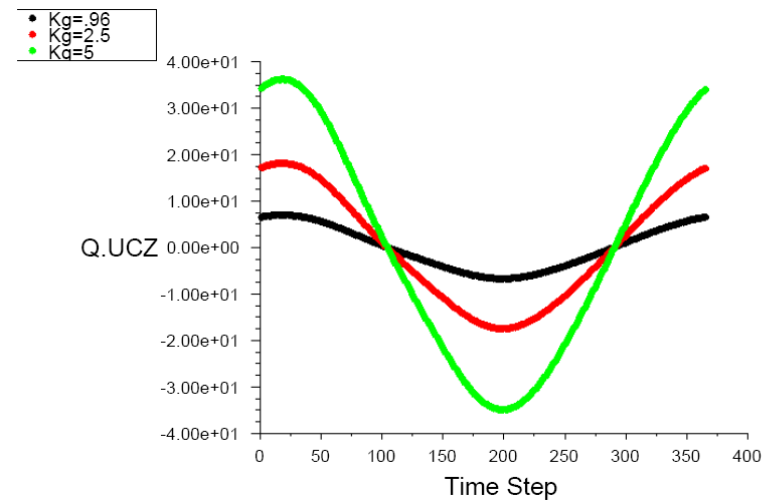

Fig. 11 The effect of the $\mathrm{kg}$ on the Q,UCZ

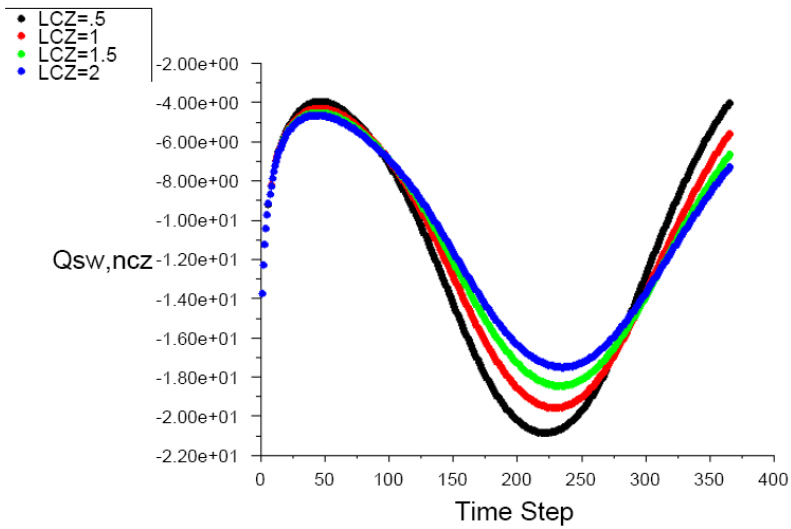

Fig. 12 The effect of the LCZ on the Qsw,ncz 


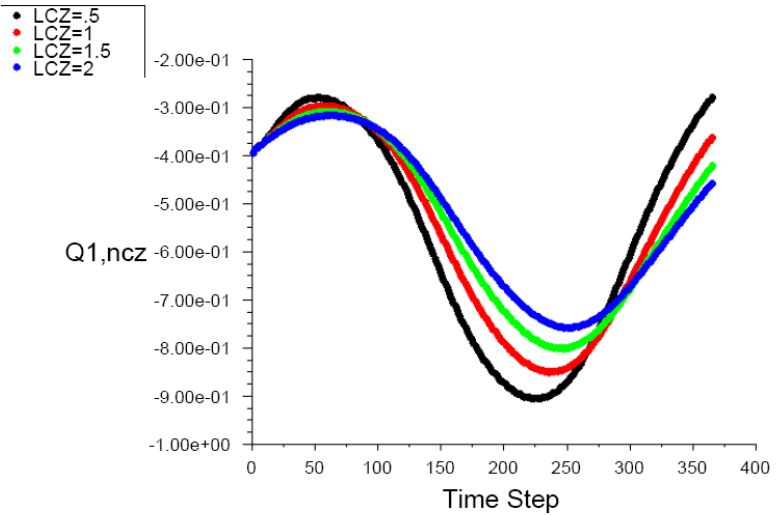

Fig. 13 The effect of the LCZ on the Q1,ncz

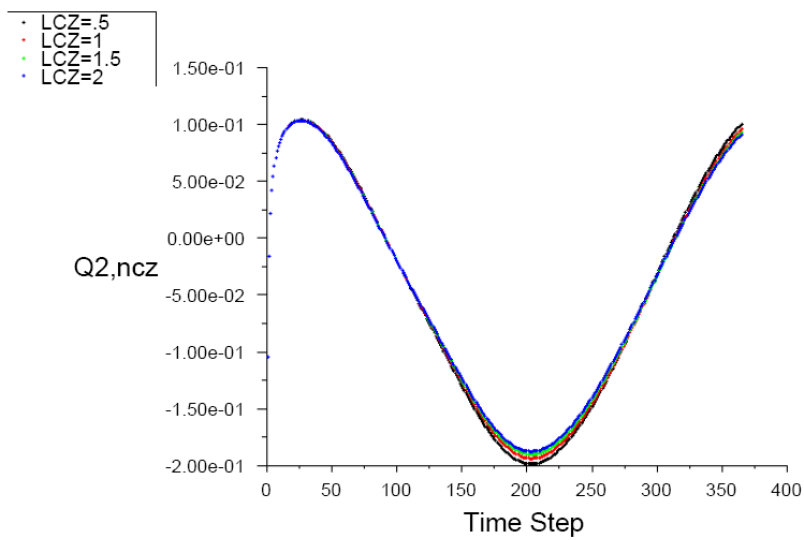

Fig. 14 The effect of the LCZ on the Q2,ncz

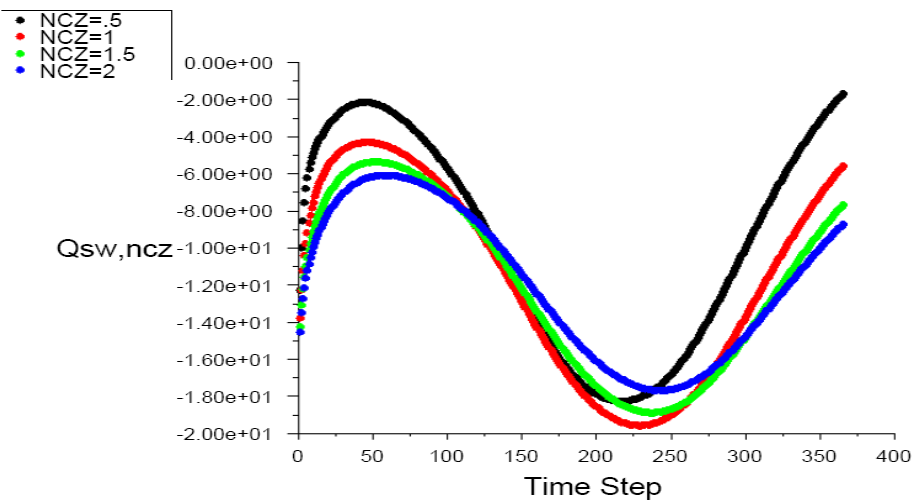

Fig. 15 The effect of the NCZ on the Qsw,ncz 


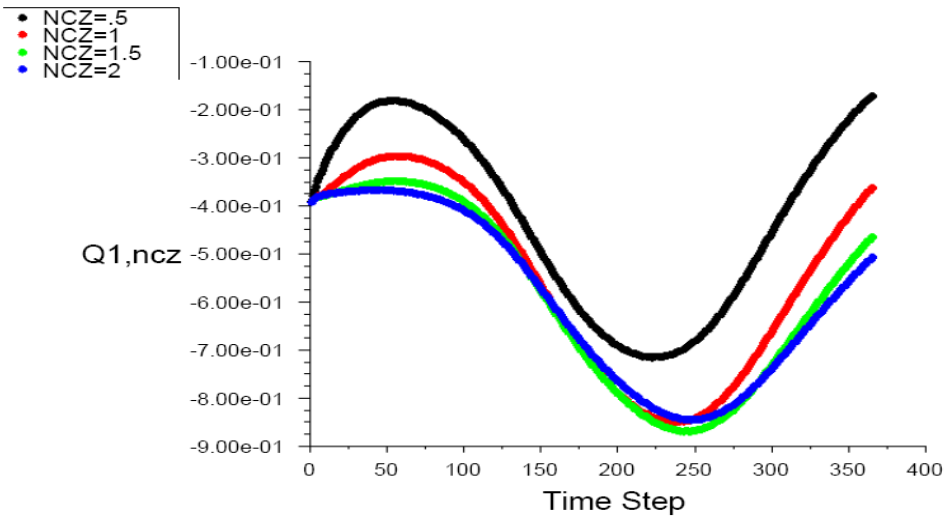

Fig. 16 The effect of the NCZ on the Q1,ncz

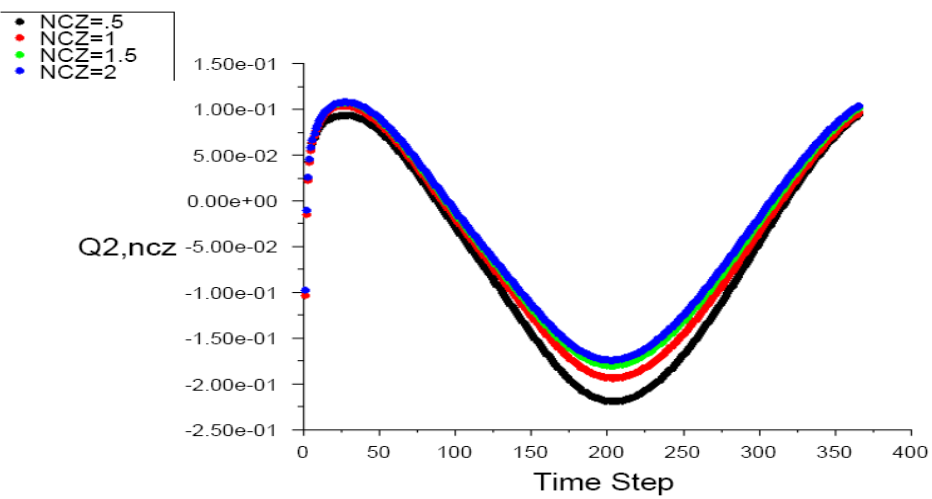

Fig17. The effect of the NCZ on the Q2,ncz

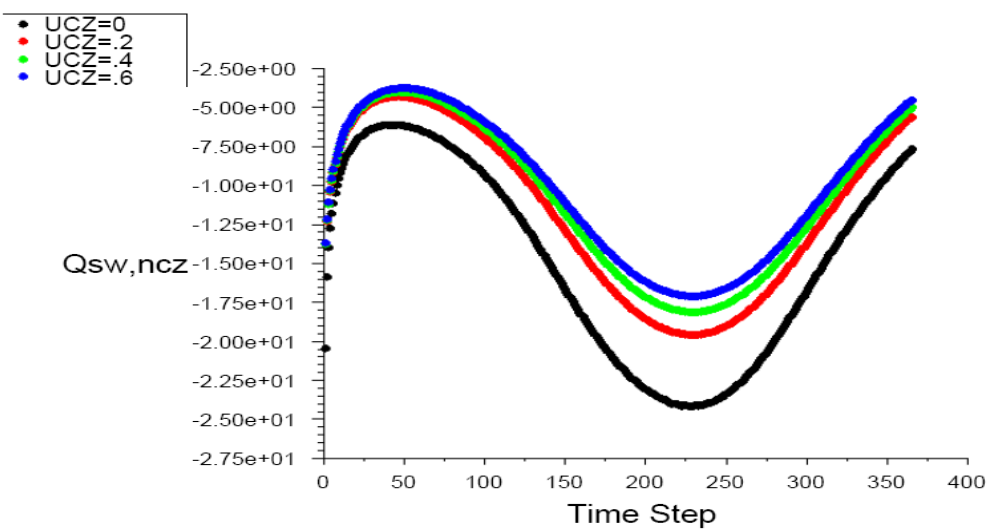

Fig. 18. The effect of the UCZ on the Qsw,ncz 


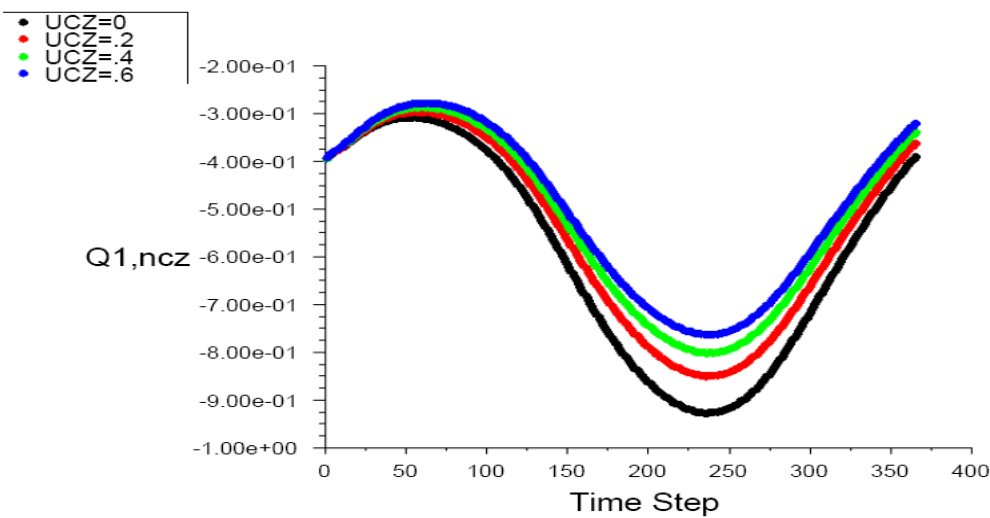

Fig. 19 The effect of the UCZ on the Q1,ncz

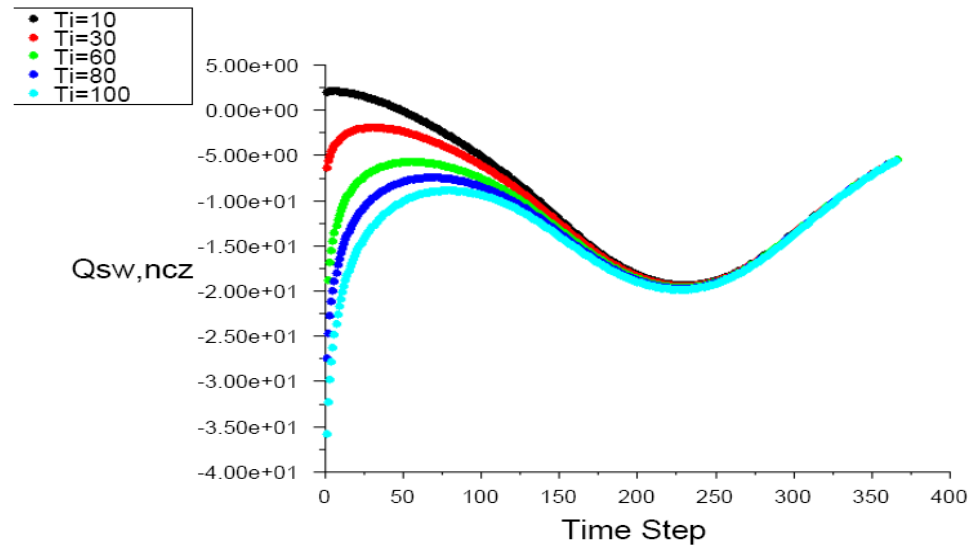

Fig. 20. The effect of the Ti on the Qsw,ncz

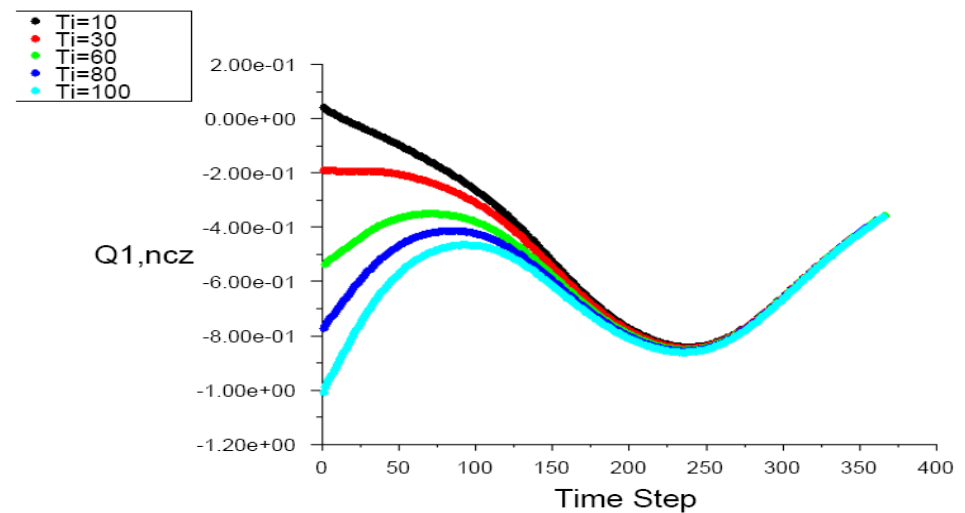

Fig. 21. The effect of the Ti on the Q1,ncz 


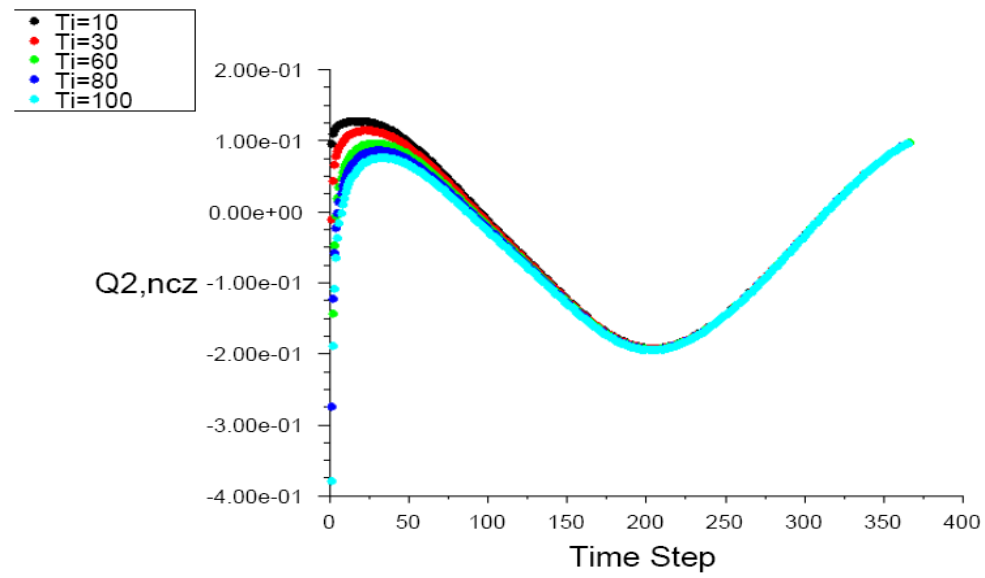

Fig. 22. The effect of the Ti on the Q2,ncz

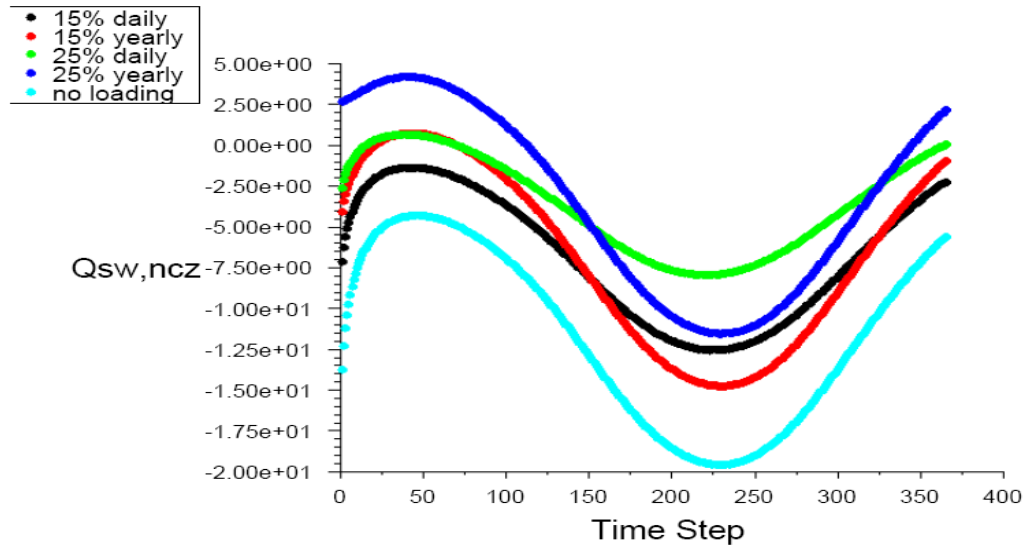

Fig. 23. The effect of loading on the Qsw,ncz

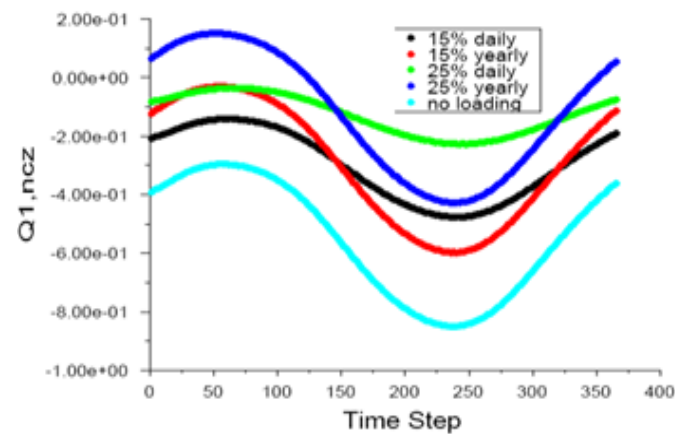

Fig. 24. The effect of loading on on the $\mathrm{Q} 1$, ncz

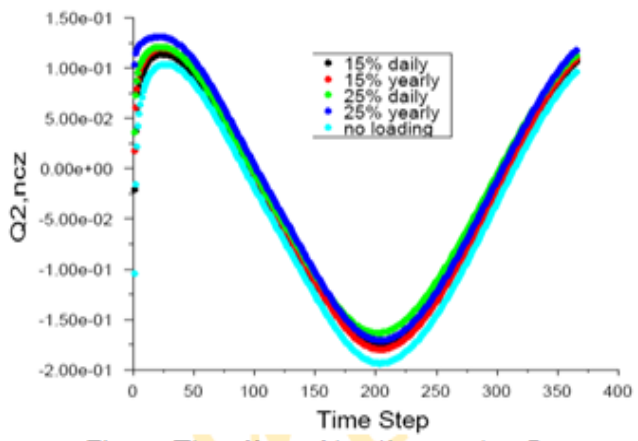

Fig. 25 The effect of loading on the $\mathrm{Q} 2, \mathrm{ncz}$ 

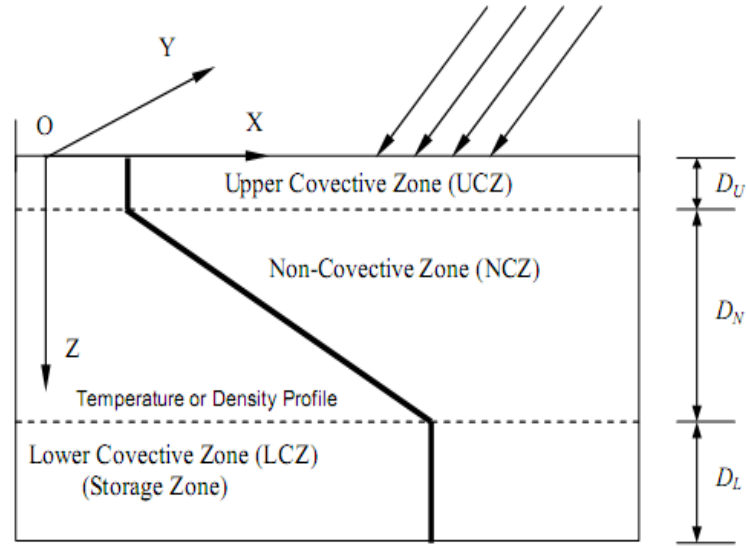

A

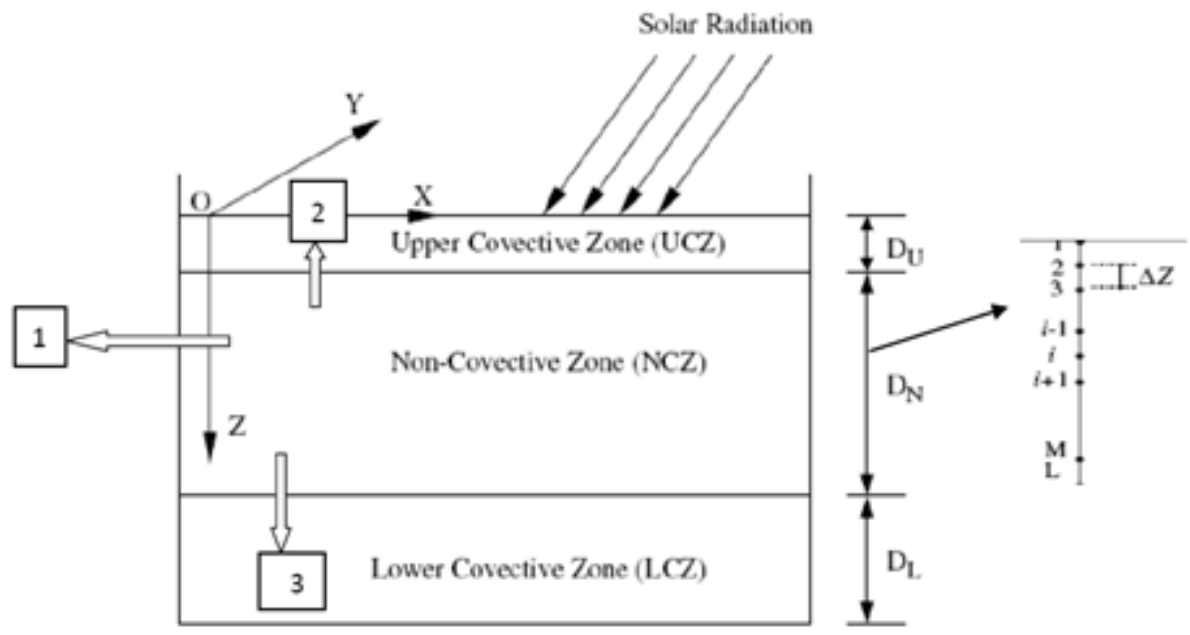

B

Fig. 26 A, B. Schematic view of a solar pond with three zones and temperature or density profile and heat transfer.

Asian Business Consortium is an independent research house committed to publishing and delivering superior, Peer-reviewed standard research 